\title{
Full-color electroluminescence from ZnO-based heterojunction diodes
}

\author{
A. Nakamura, ${ }^{\text {a) }}$ T. Ohashi, K. Yamamoto, J. Ishihara, T. Aoki, and J. Temmyo \\ Research Institute of Electronics, Shizuoka University, 3-5-1 Johoku, Hamamatsu 432-8011, Japan \\ H. Gotoh \\ NTT Basic Research Laboratories, 3-1 Morinosato Wakamiya, Atsugi-shi, Kanagawa 243-0198, Japan
}

(Received 30 July 2006; accepted 25 January 2007; published online 2 March 2007)

\begin{abstract}
Red, green, and blue electroluminescence have been observed from ZnO-based heterojunction diodes consisting of $n-\mathrm{ZnO} / n-\mathrm{Mg}_{y} \mathrm{Zn}_{1-y} \mathrm{O} / \mathrm{Zn}_{1-x} \mathrm{Cd}_{x} \mathrm{O} / p-\mathrm{SiC}$ layers. The heterostructures were grown by remote-plasma-enhanced metal-organic chemical vapor deposition. The rectifying $I-V$ characteristics at room temperature reveal the red, green, and blue wavelengths near 720, 520, and $480 \mathrm{~nm}$, respectively, when the diodes are forward biased. It is observed that the emission color can be controlled by changing the cadmium content in the emission layer. (C) 2007 American Institute of Physics. [DOI: 10.1063/1.2709913]
\end{abstract}

Wide band gap semiconductors have attracted much attention for light emitting devices in short visible wavelengths. ${ }^{1} \mathrm{ZnO}$-based heterostructures are potential candidates for applications in ultraviolet-visible range, over the GaN-based material systems. ${ }^{2} \mathrm{ZnO}$ has unique properties such as a wide direct band gap of $3.3 \mathrm{eV}$ and a large exciton binding energy of $60 \mathrm{meV}$. By doping with $\mathrm{MgO}$ or $\mathrm{CdO}$, band gaps of $\mathrm{ZnO}$ system can be modulated to the higher or the lower energy level. ${ }^{3}$ In particular, $\mathrm{Zn}_{1-x} \mathrm{Cd}_{x} \mathrm{O}$ is regarded as an ideal material having energy level in the whole visible emission range from 3.3 to $1.8 \mathrm{eV}$.

Several attempts have been made on the development of $p$-type $\mathrm{ZnO}$ and its $p-n$ junctions. ${ }^{5-8}$ However, reproducible and high quality $p$-type $\mathrm{ZnO}$ material has not been developed and hence $\mathrm{ZnO}$-based $p$ - $n$ junction device is not available. $p$-type $4 \mathrm{H}$-SiC is a suitable candidate for the $p$-type conductive substrate as a barrier layer for the $\mathrm{ZnO}$-based device, since it has wurtzite crystal structure and relatively good lattice matching to $\mathrm{ZnO}$ with a lattice mismatch of $0.5 \%$. Also $4 \mathrm{H}$-SiC substrates are commercially available. In this letter, we report on the growth and device properties of $n-\mathrm{ZnO} / n-\mathrm{Mg}_{y} \mathrm{Zn}_{1-y} \mathrm{O} / \mathrm{Zn}_{1-x} \mathrm{Cd}_{x} \mathrm{O} / p-\mathrm{SiC}$ heterojunction light emitting diodes (LEDs) for the visible full-color light emitting devices. The red-, green-, and blue-color electroluminescence were observed at room temperature.

A schematic diagram of the $\mathrm{ZnO}$-based heterojunction LED prepared by remote-plasma-enhanced metal-organic chemical vapor deposition (RPE-MOCVD) is shown in Fig. 1. Diethyl zinc, dimethyl cadmium, bis(ethylcyclopentadienylmagnesium) and oxygen gas were used as source materials. Details of RPE-MOCVD system and growth aspects are described in our previous reports. ${ }^{9,10}$ Commercial $p$-type $4 H$-SiC (0001) wafers $\left(N_{a}=2.5 \times 10^{18} \mathrm{~cm}^{-3}\right)$ were used as substrates. The substrates were cleaned in organic solvents followed by an immersion in dilute hydrofluoric acid. The substrate was preheated in a stream of $\mathrm{H}_{2}$ at $800{ }^{\circ} \mathrm{C}$ for 30 min, on which a 200-nm-thick $Z_{1-x} \mathrm{Cd}_{x} \mathrm{O}$ layer was grown at $450{ }^{\circ} \mathrm{C}$. The $\mathrm{Zn}_{1-x} \mathrm{Cd}_{x} \mathrm{O}$ layers were grown for $x$ $=0.58,0.17$, and 0.07 , having spectral range in red, green and blue (RGB), respectively. This was followed by the

${ }^{\text {a) }}$ Author to whom correspondence should be addressed; FAX: +81-53-4781321; electronic mail: ranakam@ipc.shizuoka.ac.jp growth of 400 -nm-thick $\mathrm{Mg}_{\mathrm{y}} \mathrm{Zn}_{1-y} \mathrm{O}$ epilayer as a barrier layer. The electrical properties of $n-\mathrm{Mg}_{y} \mathrm{Zn}_{1-y} \mathrm{O}$ film were examined at room temperature by Hall effect measurements using the van der Pauw configuration. The electron carrier concentration of the nonintentionally doped $n-\mathrm{Mg}_{0.04} \mathrm{Zn}_{0.96} \mathrm{O}$ film was $5.0 \times 10^{19} \mathrm{~cm}^{-3}$. After the growth of $\mathrm{Mg}_{0.04} \mathrm{Zn}_{0.96} \mathrm{O}$ layer, 10 -nm-thick $n$ - $\mathrm{ZnO}$ with electron concentration of 5 $\times 10^{18} \mathrm{~cm}^{-3}$ was grown for the $n$-type contact layer.

The heterojunction $\mathrm{ZnO}$-based LEDs with dimension of $6 \times 6 \mathrm{~mm}^{2}$ were fabricated using $10 \% \mathrm{HNO}_{3}$ aqueous solution to etch out the oxide layers to expose the edge of the $\mathrm{SiC}$ substrate. Ohmic contacts to the $n-\mathrm{ZnO}$ were made of indium $(100 \mathrm{~nm})$, which was deposited by the thermal evaporation. The backside contact was formed with $100 \mathrm{~nm}$ Au layer.

The typical current-voltage $(I-V)$ characteristics of $\mathrm{ZnO}$ based heterojunction diodes are shown in Fig. 2. The forward and the reverse $I-V$ characteristics show a rectifying behavior with a threshold of $5.6 \mathrm{~V}$ at room temperature. The threshold voltage is higher than the band gap of $\mathrm{Zn}_{1-x} \mathrm{Cd}_{x} \mathrm{O}$ or $\mathrm{Mg}_{0.04} \mathrm{Zn}_{0.96} \mathrm{O}$, owing to the contact resistance between the $p$-SiC and gold electrode. The leakage current of 6 $\times 10^{-5} \mathrm{~A}$ at the reverse bias with $-10 \mathrm{~V}$ seems to be relatively large, because the electrode contact area of the diodes is considerably large as $6 \times 6 \mathrm{~mm}^{2}$. At $6.8 \mathrm{~V}$ forward bias, the injection current reaches $40 \mathrm{~mA}$.

Electroluminescence (EL) spectra measured at room temperature for the RGB diodes with the current of 150-200 mA are shown in Fig. 3. The photographs shown in

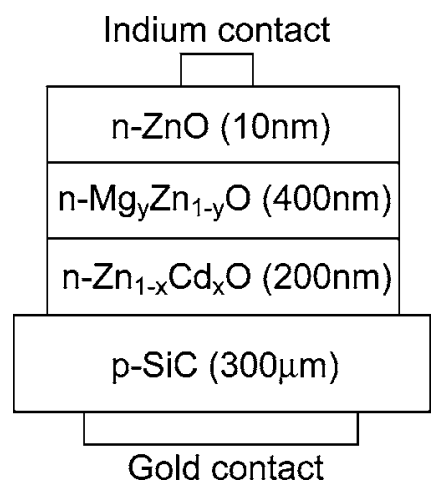

FIG. 1. Cross-sectional view shows the structure of heterojunction grown on $p$-SiC substrate. 


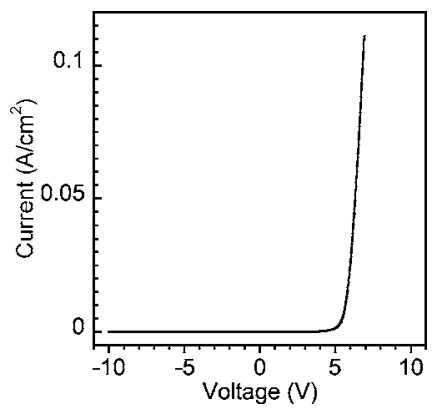

FIG. 2. Current-voltage characteristics of heterojunction diode.

Figs. 4(a)-4(c) indicate the electroluminescence images of blue, green, and red emissions in dark, respectively. The emission band with peaks at 480, 520, and $700 \mathrm{~nm}$, respectively, originate from the near interband transitions in $\mathrm{Zn}_{1-x} \mathrm{Cd}_{x} \mathrm{O}$ active region near the $p$-SiC interface. It appears that the emission intensities depend on the energy discontinuities between the $p$-SiC and the $\mathrm{Zn}_{1-x} \mathrm{Cd}_{x} \mathrm{O}$ layers or between the $n-\mathrm{Mg}_{0.04} \mathrm{Zn}_{0.96} \mathrm{O}$ layer and the $\mathrm{Zn}_{1-x} \mathrm{Cd}_{x} \mathrm{O}$ layers. The energy band diagram of $n$ - $\mathrm{Mg}_{0.04} \mathrm{Zn}_{0.96} \mathrm{O} / \mathrm{Zn}_{0.42} \mathrm{Cd}_{0.58} \mathrm{O} / p$-SiC is presented in Fig. 5. The band gaps of the active layer for cadmium contents $x$ $=0.07,0.17$, and 0.58 are $3.0,2.8$, and $2.0 \mathrm{eV}$, respectively. The electron affinity of $4 H-\mathrm{SiC}$ is $3.8 \mathrm{eV} .{ }^{11}$ The electron affinity of $\mathrm{Mg}_{0.04} \mathrm{Zn}_{0.96} \mathrm{O}$ is assumed to be linearly dependent on the magnesium content and lies between $1.7 \mathrm{eV}$ for $\mathrm{MgO}$ and $4.3 \mathrm{eV}$ (Ref. 7) for $\mathrm{ZnO}$, giving $4.0 \mathrm{eV}$ for $\mathrm{Mg}_{0.04} \mathrm{Zn}_{0.96} \mathrm{O}$. In the case of $\mathrm{Zn}_{1-x} \mathrm{Cd}_{x} \mathrm{O}$, the electron affinity is also assumed to be linearly dependent on $x$ and lies between $4.3 \mathrm{eV}(\mathrm{ZnO})$ and $4.5 \mathrm{eV}(\mathrm{CdO}),{ }^{12}$ leading to $4.4 \mathrm{eV}$ for $x=0.58$. The energetic barrier $\Delta E_{C 1}$ for electrons is

$$
\Delta E_{C 1}=\chi_{\mathrm{ZnCdO}}-\chi_{\mathrm{SiC}}=(4.4-3.8) \mathrm{eV}=0.6 \mathrm{eV},
$$

while the energetic barrier $\Delta E_{V 1}$ for holes is

$$
\begin{aligned}
\Delta E_{V 1}= & E_{g, \mathrm{ZnCdO}}+\Delta E_{C 1}-E_{g, \mathrm{SiC}}=(2.0+0.6-3.3) \mathrm{eV}= \\
& -0.7 \mathrm{eV} .
\end{aligned}
$$

The energetic barrier $\Delta E_{C 2}$ for electrons is

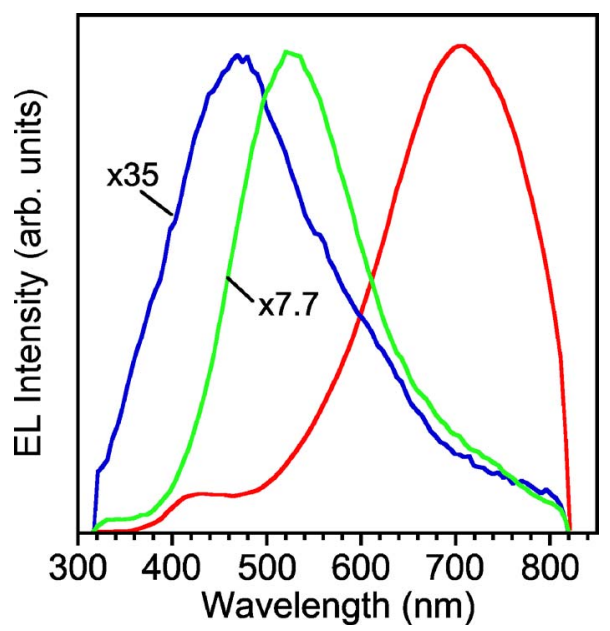

FIG. 3. (Color online) Normalized electroluminescence spectra of RGB

diodes at room temperature.
Downloaded 10 Jul 2008 to 133.70.80.50. Redistribution subject to AIP license or copyright; see http://apl.aip.org/apl/copyright.jsp

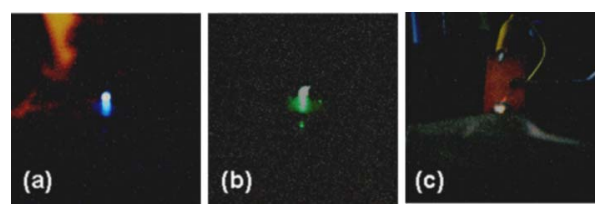

FIG. 4. (Color online) [(a), (b), and (c)] Photographs of the ZnO-based heterojunction LED sample and the emission of blue, green, and red, respectively, at room temperature.

$$
\Delta E_{C 2}=\chi_{\mathrm{MgZnO}}-\chi_{\mathrm{ZnCdO}}=(4.0-4.4) \mathrm{eV}=-0.4 \mathrm{eV},
$$

while the energetic barrier $\Delta E_{V 2}$ for holes is

$$
\begin{aligned}
\Delta E_{V 2}= & E_{g, \mathrm{MgZnO}}+\Delta E_{C 2}-E_{g, \mathrm{ZnCdO}}=(3.5-0.4 \\
& -2.0) \mathrm{eV}=1.1 \mathrm{eV} .
\end{aligned}
$$

In the case of blue emitting diode, which has $3.0 \mathrm{eV}$ as the band gap of the active layer, the valence band discontinuity $\Delta E_{V 1}$ shows a negative value, having a type II band alignment. One possibility is that the radiative transition of the blue LED takes place in the interface between the conduction band of $\mathrm{Zn}_{1-x} \mathrm{Cd}_{x} \mathrm{O}$ and the valence band of $p-\mathrm{SiC}$. The EL intensity of the blue LED was 35 times lower than that of the red LED. Even though the EL emission was broad, the emission color was controlled by changing the cadmium content in the active layer. The radiative mechanism can be mainly due to the recombination of the near interface transition at the $\mathrm{Zn}_{1-x} \mathrm{Cd}_{x} \mathrm{O}$ active region near the $p$-SiC interface.

In summary, we have presented the results of $n-\mathrm{ZnO} / n-\mathrm{Mg}_{y} \mathrm{Zn}_{1-y} \mathrm{O} / \mathrm{Zn}_{1-x} \mathrm{Cd}_{x} \mathrm{O} / p-\mathrm{SiC}$ heterojunction LEDs fabricated by RPE-MOCVD. The EL transitions were observed from the $p-n$ device at room temperature. These results on the demonstration of $\mathrm{ZnO}$-based full-color visible light emitting diodes show the potential for optoelectronic applications in ultraviolet-visible spectral range.

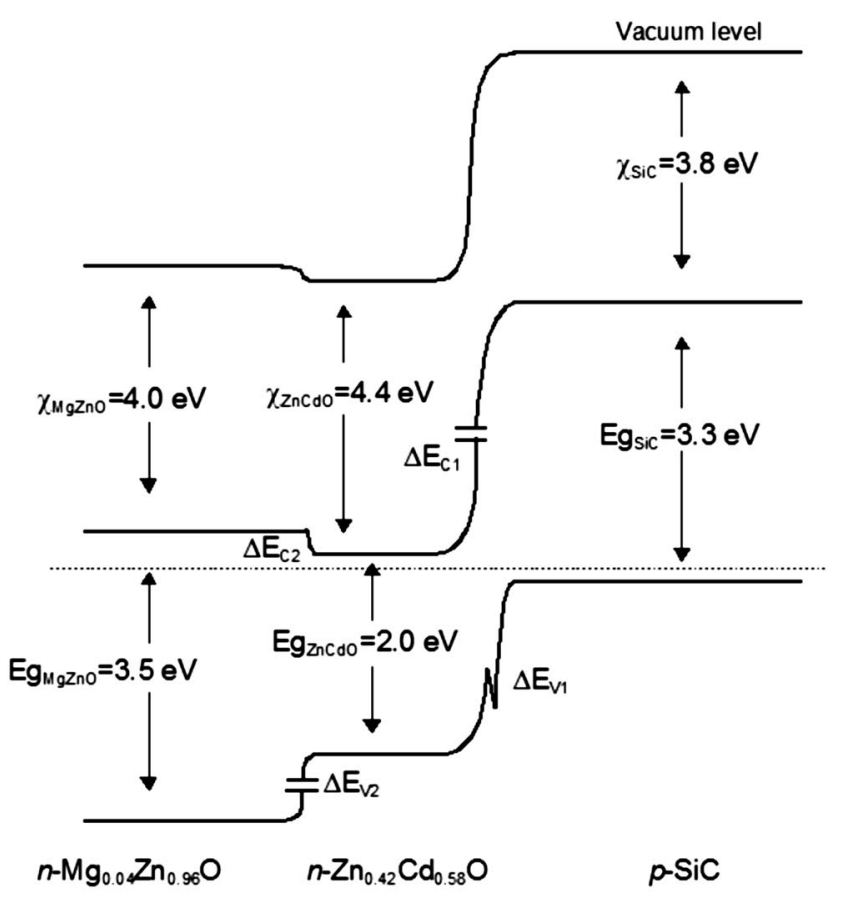

FIG. 5. Anderson model energy band diagram of $n-\mathrm{Mg}_{0.04} \mathrm{Zn}_{0.96} \mathrm{O} / \mathrm{Zn}_{0.42} \mathrm{Cd}_{0.58} \mathrm{O} / p-\mathrm{SiC}$ heterojunction.

$n-\mathrm{Mg}_{0.04} \mathrm{Zn}_{0.96} \mathrm{O} / \mathrm{Zn}_{0.42} \mathrm{Cd}_{0.58} \mathrm{O} / p-\mathrm{SiC}$ heterojunction.
AIP license or copyright; see http://apl.aip.org/apl/copyright.jsp 
${ }^{1}$ D. C. Look, Mater. Sci. Eng., B 80, 383 (2001).

${ }^{2}$ S. Nakamura, M. Senoh, N. Iwasa, and S. Nagahama, Appl. Phys. Lett. 67, 1868 (1995).

${ }^{3}$ T. Makino, Y. Segawa, M. Kawasaki, A. Ohtomo, R. Shiroki, K. Tamura, T. Yasuda, and H. Koinuma, Appl. Phys. Lett. 78, 1237 (2001).

${ }^{4}$ S. Shigemori, A. Nakamura, J. Ishihara, T. Aoki, and J. Temmyo, Jpn. J. Appl. Phys., Part 2 43, L1088 (2004).

${ }^{5}$ D.-K. Hwang, S.-H. Kang, J.-H. Lim, E.-J. Yang, J.-Y. Oh, J.-H. Yang, and S.-J. Park, Appl. Phys. Lett. 86, 222101 (2005).

${ }^{6}$ A. Tsukazaki, M. Kubota, A. Ohtomo, T. Onuma, K. Ohtani, H. Ohno, S. F. Chichibu, and M. Kawasaki, Jpn. J. Appl. Phys., Part 2 44, L643 (2005).

${ }^{7}$ Y. Alivov, E. V. Kalinia, A. E. Cherenkov, D. C. Look, B. M. Ataev, A. K.
Omaev, M. V. Chukichev, and D. M. Bagnall, Appl. Phys. Lett. 83, 4719 (2003).

${ }^{8}$ S. F. Chichibu, T. Ohmori, N. Shibata, T. Koyama, and T. Onuma, Appl. Phys. Lett. 85, 4403 (2004).

${ }^{9}$ A. Nakamura, S. Shigemori, Y. Shimizu, T. Aoki, A. Tanaka, and J. Temmyo, Jpn. J. Appl. Phys., Part 2 42, L775 (2003).

${ }^{10}$ A. Nakamura, J. Ishihara, S. Shigemori, K. Yamamoto, T. Aoki, H. Gotoh, and J. Temmyo, Jpn. J. Appl. Phys., Part 2 44, L4 (2005).

${ }^{11}$ S.-C. Changa, S.-J. Wanga, K.-M. Uanga, and B.-W. Lioub, Solid-State Electron. 49, 437 (2005).

${ }^{12}$ R. Ferro and J. A. Rodríguez, Sol. Energy Mater. Sol. Cells 64, 363 (2000). 